\title{
Use of sound spectral signals analysis to assess the technical condition of mechanical devices
}

\author{
Paweł Maciąg $^{1 *}$, and Leszek Chałko ${ }^{1}$ \\ ${ }^{1}$ Faculty of Mechanical Engineering, Kazimierz Pulaski University of Technology and Humanities in \\ Radom, Poland
}

\begin{abstract}
The article presents the results of a part of research conducted by the authors into a wide range of work on automation of public safety systems. Their main purpose is to create, on the basis of sound signals analysis, system of warning against the use of firearms monitored public places not only at the time of shooting, but at the stage of preparing - the firearm reloading process. The range of acoustic measurements presented in the article and their analyzes included variability of sound emission of selected type of firearms depending on the number of operations and thus the degree of wear. Analysis of the recorded data will allow in the future to develop a system enabling not only to determine a type of firearm or tp narrow down the search area of individual specimens, but also to determine the degree of wear in terms of suitability for further use. The results discussed in the article correspond to two states of the same firearm model. The first is the initial state from the manufacturer's factory after returning 50 control shots, the other after over 20,000 cycles. The used firearm was technically fully efficient, with no need to replace the elements during operation as well as tests. The presented scope of measurements includes spectral analysis of sound in the near field and time analysis of sound emission levels in the successive operation phases of the firearm mechanisms.
\end{abstract}

\section{Introduction}

Every working mechanical device emits sound waves regardless of its purpose. On their basis, people can make their classification, distinguish, determine location, etc. with the help of the sense of hearing This ability allows not only for recognizing the type of a working machine, but also identification of a specific kind, which can be exemplified by a particular type of car from a group of motor vehicles.

Audible frequencies for a healthy human body range from $20-20,000 \mathrm{~Hz}$. Sound waves with a pressure of up to $40 \mathrm{~dB}$ are perceived as quiet, above $60 \mathrm{~dB}$ they give the impression of increased loudness and values of 80 and more $\mathrm{dB}$ are treated as noise and can be harmful and in some cases even dangerous for our health.

\footnotetext{
* Corresponding author: p.maciag@uthrad.pl
} 
When a human ear is exposed to impact noise at a sound intensity of $120 \mathrm{~dB}$ or higher, there is a risk of acoustic trauma, changes to the hearing threshold, or noise-inducedhearing-loss [1]. Therefore numerous studies are performed to evaluate hearing protection systems used by police officers exposed to activities at shooting ranges [2]. However, while shotguns and artillery report is considered to be just a noise, it can be in fact very informative. Acoustic signal of a firearm discharge can be detected and classified [3]. For example, Defense Technical Information Center published a study of the spectral content of small arms fire at varying distances [4]. In the study, two components of small-arms noise were distinguished: the muzzle blast and the sonic boom. In another approach aimed at a pattern recognition, shock wave, muzzle blast and reflections were distinguished, and gunshot signatures were divided into multiple classes [5].

To analyze sound pressure levels generated by firearms with and without suppression devices, certified measuring devices are produced [6].

Another problem solved with acoustic signal analysis is localization of a shooter. The respective systems use the muzzle blast and acoustic shock waves to compute the shooter's location [7]. An analysis based on Acoustic Gun Shot Detector for small fire arms was reported, with utilization of the Acoustic Characteristics of small firearms based on recorded data and test results of field trials [8]. Even though the systems designed for gunshot localization have been developed since the early 1990's, they still need to be improved. In particular, three specific problems related to the processing of gunshot acoustic signatures should be addressed: direction-of-arrival estimation, noise cancellation, and issues related to multipath propagation [9].

Recently, gunshot detection has become an issue. It has found widespread applications from systems aimed to protect elephants in Africa [10] to the ones installed in an urban neighborhood plagued by high rates of violent crimes [11]. Perhaps the most chilling challenge were the multiple school shootings occurring in February and May 2018 in the USA, which motivated to installation of systems for instant detection of gunshots and identification of weapons in schools [12].

It needs to be said that a bullet leaves a gun with an initial velocity of ca. $1000 \mathrm{~m} / \mathrm{s}$, while sound velocity in the air at $20^{\circ} \mathrm{C}$ is ca. $340 \mathrm{~m} / \mathrm{s}$. Obviously, when a gunshot sound is registered, it is too late. The following investigations address the issue of weapon reloading, which usually takes place several seconds before shooting [13].

The article presents a small fragment of measurements carried out by the authors as part of their work on automation of public safety systems.

During our previous firearms studies, it was noticed that acoustic emission of the reloading process depends not only on the type of weapon [14], but also on the quality of work and number of shots. This was the reason for starting research to determine the degree of wear of a particular type of weapon based on acoustic measurements.

The main goal of the prepared system is automatic detection of reloading of weapon type and specimen before shooting and shooting in public places covered by audio-video surveillance (e.g. public offices, banks, museums, etc.) by means of sounds analisis.

\section{The sound pattern as the basis for identification of type and degree of wear}

Human beings are able to recognize sounds and to identify their sources naturally. However, the challenge of acoustic signal recognition and discrimination between emissions from different acoustic emissions (AE) is far from simple. The pattern recognition methods can be based on computerized extracti of features of $\mathrm{AE}$ waveforms from an unknown source and then comparing these features with those predicted for possible sources using theoretically and experimentally determined models of sources and calibration studies [15]. 
A new approach was reported, based on an exhaustive screening taking into account all combinations of signal features extracted from recorded acoustic emission signals. For each possible combination of signal features an investigation of the classification performance of the k-means algorithm was evaluated and calculated utilizing the Davies-Bouldin and Tou indices, Rousseeuw's silhouette validation method and Hubert's Gamma statistics. As a second step, a numerical ranking was performed using results of cluster validation methods. This methodology was proposed as an automated evaluation of the number of natural clusters and their partitions without previous knowledge about the cluster structure of acoustic emission signals [16].

In the most recent solutions, after feature extraction and selection, further classification is based on artificial neural network (ANN) [17].

In order to recognize leaking of natural gas, dominant frequencies of the AE leak signals were validated and the feature sets \{Peak, Mean, Peak Frequency, Kurtosis\} and \{Mean, Peak Frequency $\}$ were applied. Another proposed leakage detection scheme using an acoustic emission sensor was based on kernel principal component analysis and the support vector machine (SVM) classifier for the leakage level recognition [18].

A different approach proposed to estimate the leakage rate of a valve in a natural gas pipeline via factor and cluster analysis of acoustic emission signals [19]. Three types of clustering algorithm-fuzzy $C$ means, $k$-means and $k$-medoids-were used to classify leakage rates. One of the most obvious applications of the acoustic signal recognition is the monitoring of friction couples. It was reported that during friction and wear experiments performed with a pin-on-disk-type sliding-friction tester with an electric current flowing between the specimens, an analysis of the frequency of the resulting AE signal showed that each phenomenon produced a distinct AE frequency spectrum [20].

Another study proposed application of acoustic emission analysis for in situ monitoring of sliding surfaces until their failure due to scuffing mechanism [21]. Here, three regimes of events have been specified; steady-state, pre-scuffing, and scuffing according to the friction behavior. During the analysis, acoustic signals for each regime have been decomposed with wavelet packets, with sub-band energies as an analysis features.

Vibro-acoustic noise emitted during various machine operations can be highly informative. Relationship between rock properties and the vibro-acoustic signal characteristics generated by drilling was investigated, and a special wideband acoustic sensor method was applied to distinguish the specific time-frequency characteristics generated by drilling in different types of rock [22]. In addition, time domain and timefrequency analyses were applied to analyze differences between signal characteristics generated by different kinds of rock. It was found that the acoustic sensor approach presented better signal-to-noise ratio than the vibration sensor approach.

Many studies are devoted to acoustic signal used for supervision of machining processes. For example, improved efficiency of machine state identification from AE data was reached when features extracted in both time and frequency domains were combined and then reduced with the linear discriminant analysis [23]. A high-frequency acoustic emission signal with further acquired data was used to develop characteristic factors to predict product quality and to detect tool defects [24]. In one study, acoustic signals were captured for an entire grinding cycle until abrasive grains of girding wheel become dull [25]. Various features of the acoustic emission signatures were extracted from the timedomain and correlated with the surface roughness. Good condition and dull condition of the grinding wheel are predicted using machine-learning techniques such as decision tree, artificial neural network, and support vector machine. Another group reported researches into Acoustic Emission Monitoring of Robot Assisted Polishing [26].

Here, a pre-processing phase was introduced to remove the bias generated by the AE raw signals. The signals were subjected to two feature extraction procedures: (1) a 
conventional one based on statistical analysis, and (2) an advanced one based on wavelet packet transform (WPT). The statistical analysis and WPT pattern feature vectors were utilized as inputs to neural network for decision making data processing.

Acoustic emission analysis was appiled to damage diagnostics in the middle of 20th century when Josef Kaiser detected audible sounds produced by deformation under tensile test on metallic specimens, which is known nowadays as "the Kaiser effect" [27]. Schofield and Tatro improved the instrumentation and clarified the source of AE during plastic deformation. In the 1960s, AE has been applied as a nondestructive testing (NDT) method in the aerospace industry, and in the early 1970s research started on fiber-reinforced composites testing. Recently, an AE technique monitoring in plain and steel fiber reinforced concrete specimens was analyzed using unsupervised kernel fuzzy cmeans pattern recognition and the principal component method to categorize various damage stages [28]. Results were reported on AE signatures of synthetic mooring ropes subjected to sinusoidal tension-tension loading in a controlled environment [29], a possible correlation between the dominant failure in glass fibrereinforced plastics and their corrwsponding acoustic emissions was reportedly evaluated [30], the Identification of Active Damage Processes acoustic emission method was reported to be applied to continuous monitoring of active destructive processes in reinforced concrete bridges [31].

\section{Test conditions and apparatus}

Acoustic measurements are highly dependent on physical conditions of experimentation. In particular, field measurements are significantly different from those performed in closed rooms, where reflected sounds play important roles and have their impact on measurement results. Closed room measurements require appropriate definition of acoustic conditions in order to choose proper methods and apparatus. Important factors should be taken into consideration, such as physical dimensions of an analyzed object, dimensions of a room where measurement is performed, noise, air movement inside the room, and eventually humidity and temperature.

The respective fields corresponding with direct and reflected sounds in an open space and closed rooms are shown in Figures 1 and 2.

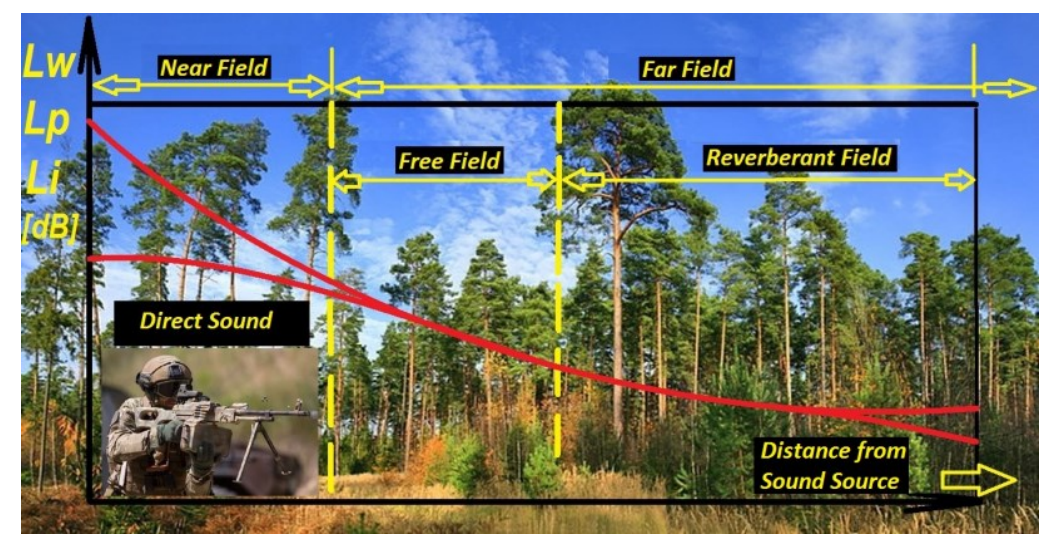

Fig. 1. Acoustic conditions in open air [14].

Acoustic measurements in the field close to the sound source require application of energy measurement methods such as intensity or sound power measurement. Sound intensity (SIL) and sound power describes the fellowing values: 


$$
\begin{aligned}
& L_{I}=10 \cdot \log \frac{I}{I_{0}}, \\
& L_{W}=10 \cdot \log \frac{W}{W_{0}},
\end{aligned}
$$

where $I$ and $I_{0}$ are sound intensity at the measuring point $\left[\mathrm{W} / \mathrm{m}^{2}\right]$ and reference sound intensity $I_{0}=1\left[\mathrm{pW} / \mathrm{m}^{2}\right]$, respectively. Similarly, $W$ and $W_{0}$ are sound power of an examined source [W] and reference sound power $W_{0}=1[\mathrm{pW}]$, respectively.

Both SIL and SWL values are logarithmic ones related to human perception addressed by WeberFechner law, postulating that an external stimulus is scaled into a logarithmic internal representation of sensation [33].

However, due to the short-term nature of the weapon reloading process, these methods could not be used due to low repeatability of the obtained results. Therefore, decision was made to perform acoustic measurements in the free field by moving the measurement microphones to a distance of 1.5 meters from the tested object (more than twice the size of the tested weapons).

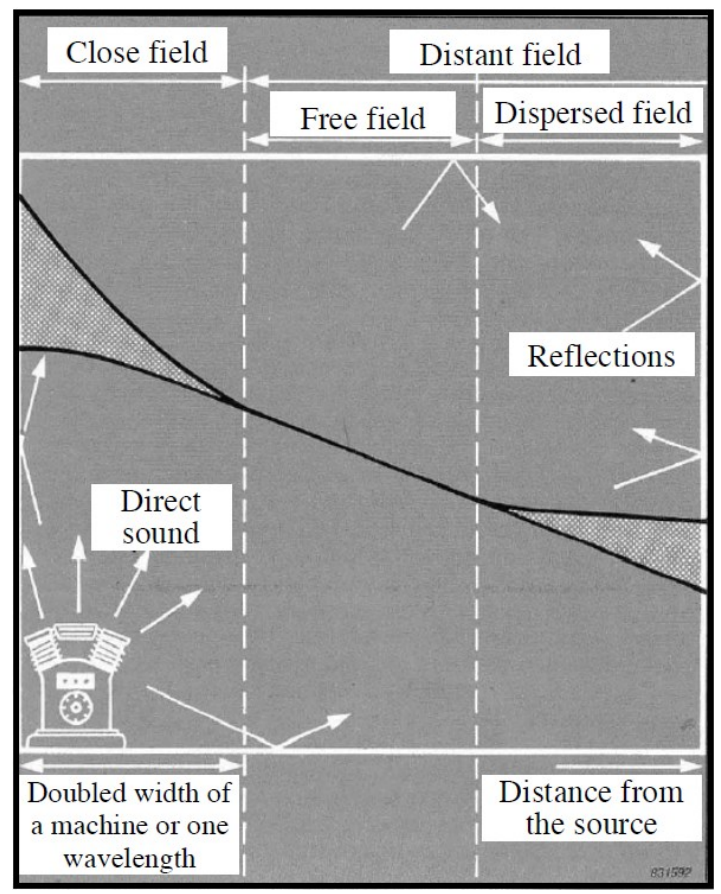

Fig. 2. Acoustic conditions in a closed room [32].

Sound pressure measurements (SPL) were made and each of over 25 measurements (for each object) lasted 2 seconds. Sound pressure level (SPL) measurement defines changes of acoustic pressures in the free or dispersed field. SPL is the local pressure deviation caused by a sound wave related to the ambient atmospheric pressure, average or equilibrium. Sound pressure $L_{p}[\mathrm{~dB}]$ is defined as follows:

$$
L_{p}=10 \cdot \log \frac{p}{p_{0}}
$$


where $p$ and $p_{0}$ are sound pressure and reference sound pressure [Pa], respectively. The value of $p_{0}=2 \times 10^{-5} \mathrm{~Pa}$.

The acoustic experimentation was carried put with Brüel \& Kjaer 2260 analyzer including a sensing microphone system 3595. Apart from standard software for onemicrophone measurements, the device featured BZ7205 application that enabled to measure the sound power level using the sound intensity method. The sound analyzer with the twomicrophones probe is shown in Figure 3.

The system had a current calibration certificate No. 3290/2017 from the accredited laboratory HAIK sp. z o.o.

Before each measurement series, the device was calibrated using the sound calibrator type 4231 (B\&K).

Due to the relatively short time of the weapon reloading process, the authors decided to register the sound using the digital oscilloscope DSO-2902 directly connected to the analog outputs \#1 and 2 of the 2260 Investigator sound analyzer. This way, the "pure" signal was obtained without any additional processing. Thus, a quick real-time signal was recorded with no deformations typically caused by corrections aimed to apart analyzed frequencies to the human perception. Type 4189 microphones had a sensitivity of $50 \mathrm{mV} / \mathrm{Pa}$. An acoustic signal of $94 \mathrm{~dB}$ caused generation of $50 \mathrm{mV}$ alternating voltage in the microphone output. Similarly, $74 \mathrm{db}$ signal (i.e. $20 \mathrm{~dB}$ lower) generated 10 times smaller voltage (i.e. 5 $\mathrm{mV}$ ), signal $54 \mathrm{~dB}$ (i.e. $40 \mathrm{~dB}$ lower) generated 100 times smaller voltage, et cetera. Thus, two independent systems recored simultaneously the same signal.

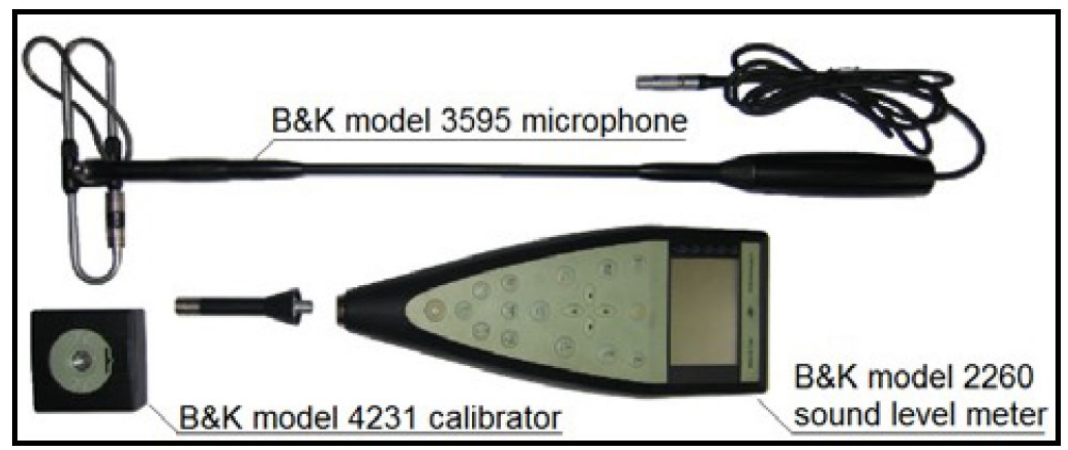

Fig. 3. Brüel \& Kjaer 2260 sound analyzer with measuring microphones and calibrator.

Measurement of the impact of wear and tear on continuig suitability of the tested objects in the case of firearms required a strict determination of the phase of the reloading process, which is directly related to the positioning of internal mechanisms. Therefore, the equipment of the test stand supplemented with a fast camera recording the process of movement of the mechanisms with oscilloscope sampling frequency that is about 2,000 frames per second. Photographs from the measurements are presented in Chapter 3. The view of the test bench is shown in Figure 4.

On the basis of future measurements, the authors will continue to work on developing a system for determining correction factors that allow for taking into account "wear and tear" relative to the standard record, which will provide the basis for narrowing the set of wanted weapons.

This approach will determine further research aimed at weapon identification based on the reload sound. 


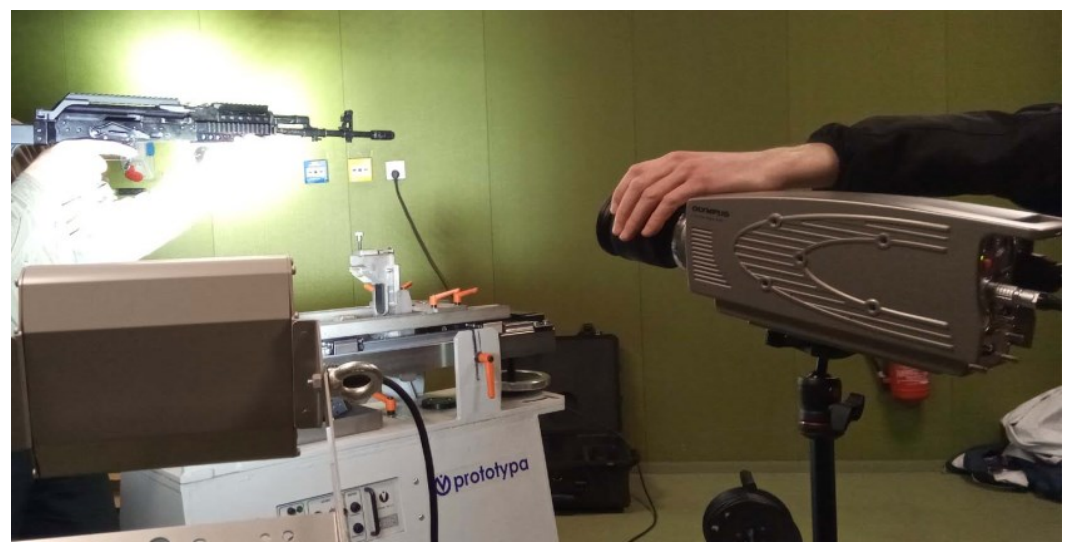

Fig. 4. Test stand during the measurements.

The condition of wear has a huge imapct on the sound emitted. Effects of wear on sound emission were measured in studies on variability of sound characteristics of weapons in order to function as a shots number. For this purpose, an assault weapon with a design derived from the well-known AKM model was selected a modified assault semiautomatic rifle "Beryl" cal. 5.56x45 made by Fabryka Broni S.A. in Radom.

The tests were carried out on a specimen subjected to a lifetime testing and, consisted in giving required number of shots and controlsling, whether the dimensional and utilitarian parameters of the weapon meet technical requirements of military acceptance. Among other things, accuracy, focusing of missiles on the target, and general correctness of the weapon's operation are evaluated.

The following are the measurement results corresponding to the two states of the same weapon. The initial condition is as new, corresponding to the handing of 50 shots and the other state is after giving 20,050 shots. Weapons are technically efficient and, meet the technical conditions of acceptance, without replacing any parts pr components during testing.

Basic technical data are presented in Table 1 while Figure 5 shows the view of the rifle.

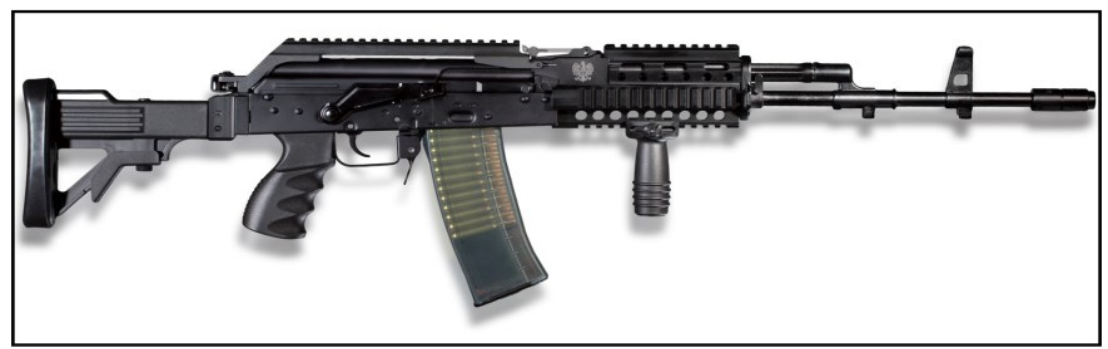

Fig. 5. BERYL S 223 Semiautomatic rifle [34].

.Table 1. BERYL S 223 - technical data [34].

\begin{tabular}{|c|c|}
\hline Caliber: & $.223 \mathrm{Rem}$ \\
\hline Muzzle velocity: & $\mathrm{V}_{0}=920 \mathrm{~m} / \mathrm{s}$ \\
\hline Muzzle energy: & $\mathrm{E}_{0}=1690 \mathrm{~J}$ \\
\hline Firing mode: & single \\
\hline
\end{tabular}




\begin{tabular}{|c|c|}
\hline Type of action: & gas-operated weapon \\
\hline Number of grooves: & 6 \\
\hline Rifling pitch: & $228 \mathrm{~mm}$ \\
\hline Magazine capacity: & 10,20 and 30 rounds \\
\hline DIMENSIONS: & $980 \mathrm{~mm}$ \\
\hline Length with telescopic butt extended: & $910 \mathrm{~mm}$ \\
\hline Length with telescopic butt pushed: & $457 \mathrm{~mm}$ \\
\hline Tube length: & \\
\hline WEIGHTS: & $3650 \mathrm{~g}$ \\
\hline Weapon, empty: & $185 \mathrm{~g}$ \\
\hline Magazine (30 rds) empty: & $554 \mathrm{~g}$ \\
\hline Magazine (30 rds) loaded: & \\
\hline
\end{tabular}

\section{Results and discussion}

The spectral analysis of sound pressure (SPL) is shown in Figure 6. Each of the recorded bands is an average of 25 measurements of the Beryl rifle reload process. For a better comparison of the results, the diagram shows the recorded results for a new item after 50 test shots (empty bars) and one after returning more than 20,000 shots (filled bars). Table 2 contains averages of 25 measurements of recorded $\mathrm{L}_{\mathrm{eq}}$ (Equivalent continous level of Sound pressure) using the correction A-frequency-weighting as well as without the correction Lin.

Table 2. Equivalent continous level of Sound pressure $\mathrm{L}_{\mathrm{eq}}$ measured during tests.

\begin{tabular}{|c|c|c|}
\hline Type of weapon & $\begin{array}{c}\text { Leq }(\mathrm{L}) \text { (Equivalent } \\
\text { continous level of } \\
\text { Sound pressure) }\end{array}$ & $\begin{array}{c}\text { Leq }(\mathrm{A}) \text { (Equivalent } \\
\text { continous level of } \\
\text { Sound pressure) }\end{array}$ \\
\hline $\begin{array}{c}\text { BERYL S 223 } \\
\text { after 50 shots }\end{array}$ & $81.54 \mathrm{~dB}$ & $81.00 \mathrm{~dB}$ \\
\hline $\begin{array}{c}\text { BERYL S 223 } \\
\text { after 20 050 shots }\end{array}$ & $80.39 \mathrm{~dB}$ & $80.86 \mathrm{~dB}$ \\
\hline
\end{tabular}




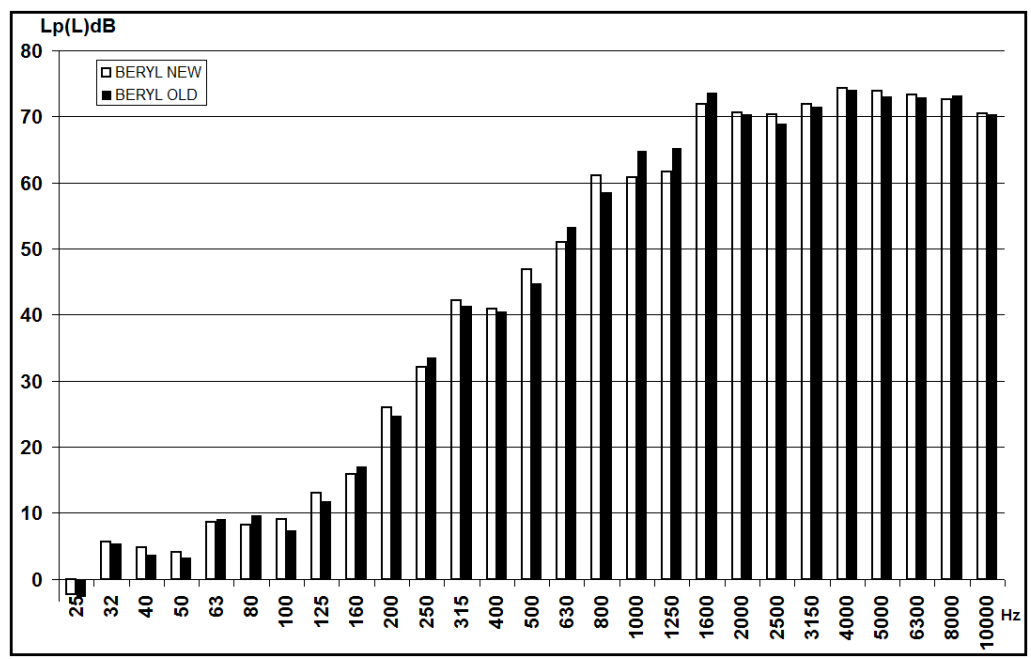

Fig. 6. Spectral analysis in the $1 / 3$ octave band of sound pressure $L p(L)$ for reloading Beryl S 223 rifle.

The frames showed below in Figures 7-9 illustrate the 3basic reloading phases later referred as "A", "B" and "C". The phase "A" - reloading initiation, i.e. sharp jerking of the slide handle, as shown in the following Figures 10-13. This phase begins with a slow increase of the signal amplitude in the first millimeter of displacement, then the sound amplitude increases significantly because of the interaction of the cam slide with the lock and unlocking. The end of the unlocking cycle and displacement of the slide to the rear extreme position starts the phase "B". Here, the spring-driven return mechanism releases the mechanical energy to the slider unit, and the amplitude of the vibrations decreases. Before the start of "C" phase, the lock contacts the tube holder and the cams force its turn locking it. Then the phase " $\mathrm{C}$ " can be identified as a strike of the slider against the tube holder, which generates noise. This involves a series of vibrations transferred across the entire rifle's structure.

The huge amount of collected data allowed for preliminary confirmation of the ability to identify the state - determine the number of shots cast - based on the sound emitted.

Below are 4 selected oscillograms from sound recording for the first and the last measurement cycle, after 50 (Fig. 10 and 11) and 20050 shots (Figs. 12 and 13) respectively. Letters "A", "B" and "C" are shown on every oscillogram Figure for the general orientation of the reader around the processes that cause the sound.

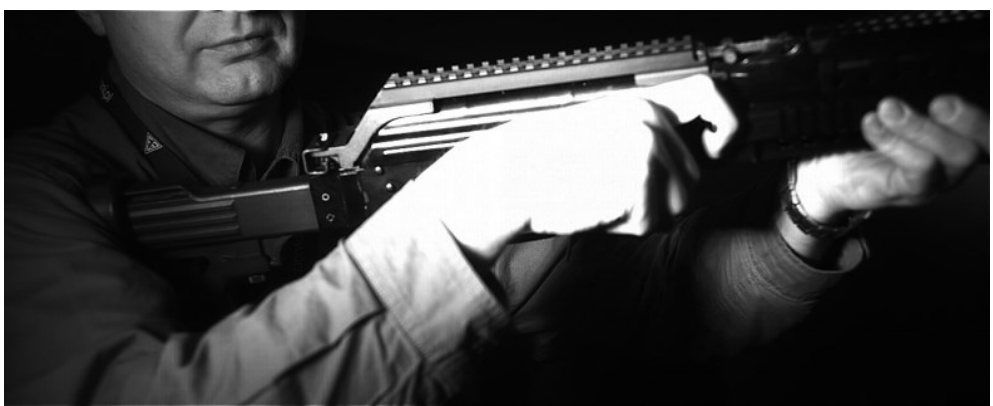

Fig. 7. The beginning of the reloading process - phase "A". 


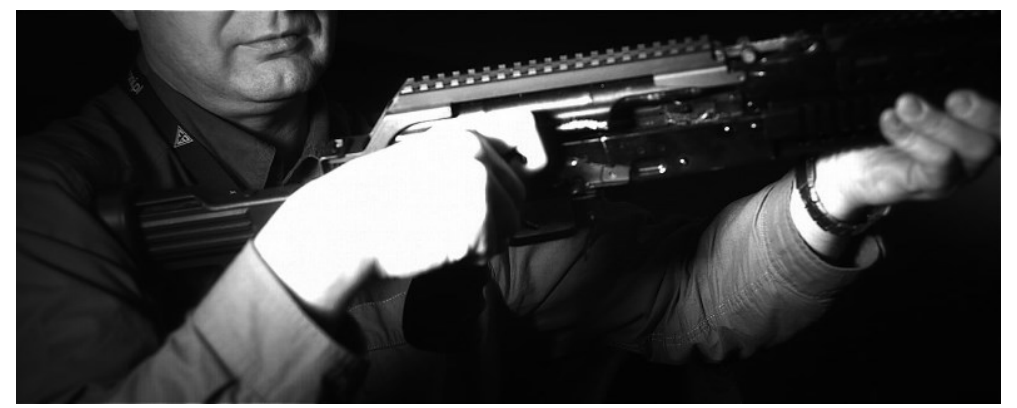

Fig. 8. End of the movement backwards: the slider is striking the butt holder - phase "B".

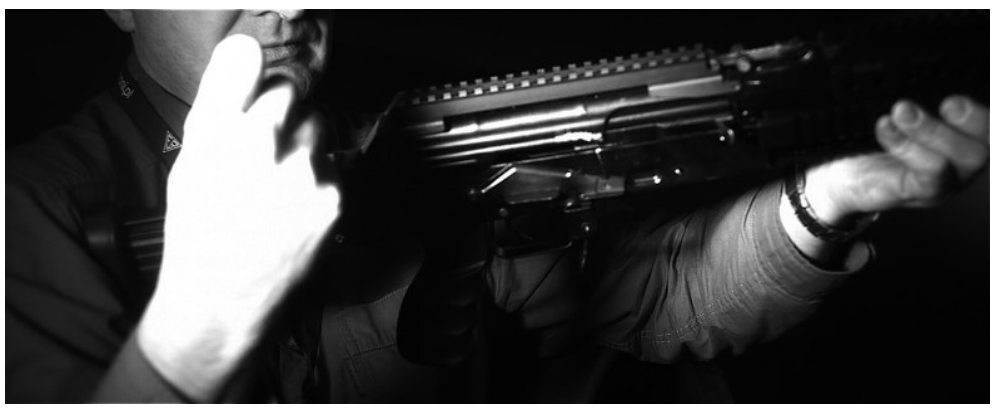

Fig. 9. The end of the forward movement, the slider is striking the tube holder - phase "C"

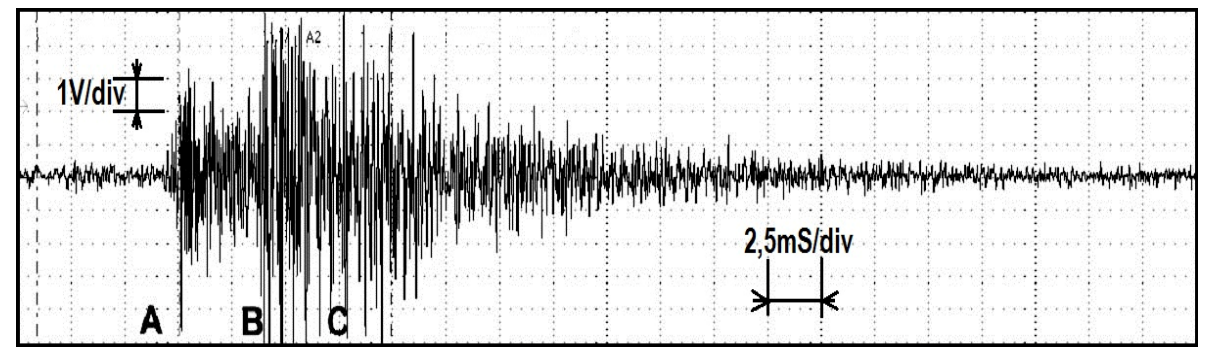

Fig. 10. Reloading sound oscillograph No. 01 - Beryl S 223 rifle after 20050 shots.

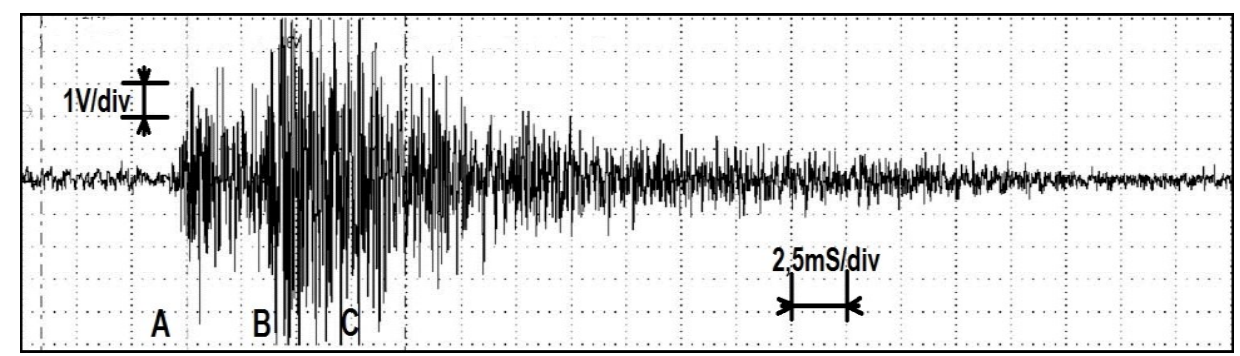

Fig. 11. Reloading sound oscillograph No. 25 - Beryl S 223 rifle after 20050 shots. 


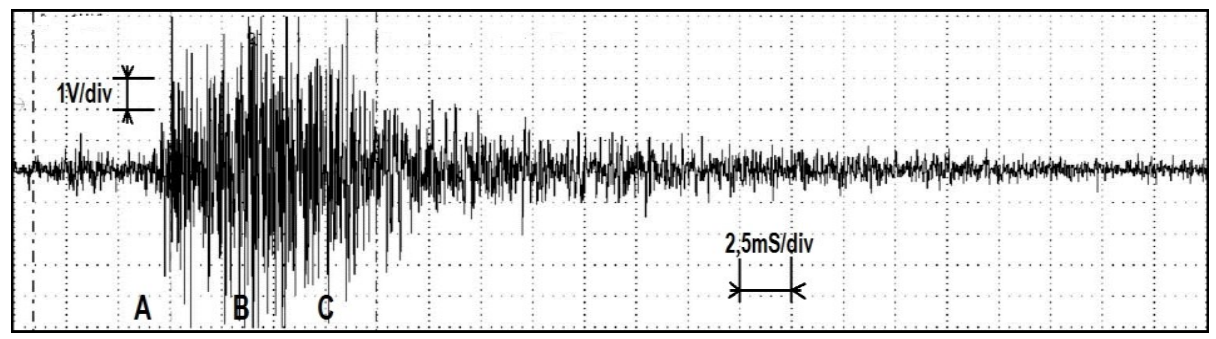

Fig. 12. Reloading sound oscillograph No. 01 - Beryl S 223 rifle after 50 shots.

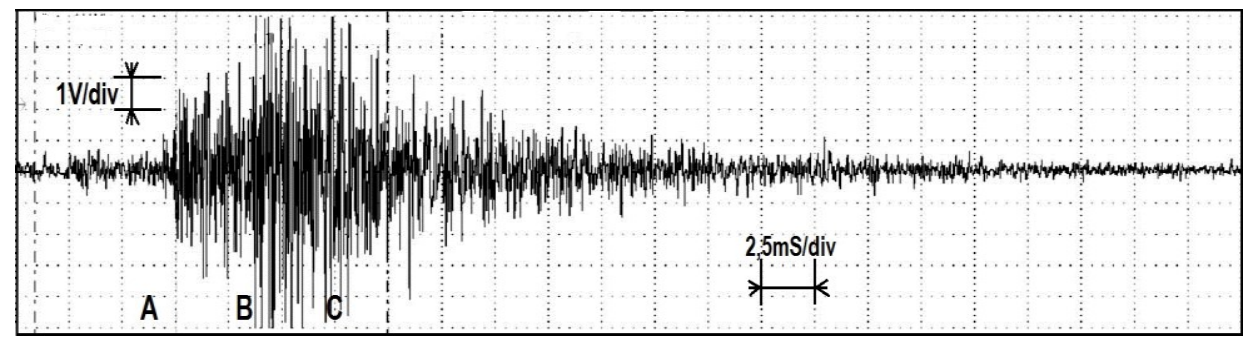

Fig. 13. Reloading sound oscillograph No. 25 - Beryl S 223 rifle after 50 shots.

A comparison of the oscillograms in Figures 10 and 11 with the oscillograms in Figs.12 and 13 shows the possibility of measuring the status of weapon wear. A significant difference between them results from the state of reaching the interacting surfaces. In the new condition, the item generates a significantly higher amount of noise during the return phase of the slider (between letters A and B, Figures 12 and 13). In addition, the time characteristics of the waveforms resulting from the change in traffic resistance change.

A significant amount of measurements carried out so far requires further analysis. In order to create an optimal algorithm that takes into account the identification of firearms on the basis of sound, the degree of its consumption requires further research on a significantly larger number of items.

\section{Conclusion}

Based on the registered data and analysis of the results, we can formulate the following conclusions:

- the technical condition of weapons and the number of shots fired affect acoustic emissions,

- Number of work cycles of the tested Beryl rifle increases as sound pressure level rises, which is related to the changing in automation components resistance motion,

- the spectral analysis of the tested weapons showed lower sound pressure values in the majority of tested rifle bands with larger number of shots,

- the sound of the rifle with larger number of work cycles clearly differed from that of the new rifle and was perceived as more "softer" on the human ear,

- for correct analysis of the technical condition of a particular kind and type of weapon it is necessary to use additional measuring devices with a high sampling frequency (e.g. digital analyzers),

- creation of an algorithm for identification of firearms, taking into account levels of wear and tear, requires additional testing on more weapons of a certain type with a different number of shots. 
Acknowledgments: The research has been counted due to financial support by the Ministry of Science and Higher Education in Poland, research funds No. 3270/22/P on the subject "Sound emission of machines and devices."

The authors express their gratitude to Fabryka Broni „Eucznik” - Radom sp. z o.o. for enabling the measurements.

\section{References}

1. H.L. Guida, Th.H., Kinoshita S.K., Diniz, Braz. J. Otorhinolaryngol., 77(2), 163-170 (2011)

2. H.L. Guida, C.L.Taxini, de Oliveira Gonçalves C.G., Valenti V.E., Braz. J. Otorhinolaryngol., 80(6), 515-521 (2014)

3. Luzi L., Gonzalez E., Bruillard P., et al., J. Acoust. Soc. Am., 139(5), 2723-2731 (2016)

4. S. Peterson, P. Schomer, Acoustic Analysis of Small Arms Fire, USACERL Technical Report EC-94/06, Available at http://www.dtic.mil/dtic/tr/fulltext/u2/a278306.pdf, (1994)

5. U. Libal, K. Spyra, Expert Syst Appl., 41(11), 5097-5104 (2014)

6. https://www.pcb.com/ContentStore/mktg/LD_Brochures/LD_LxTQPR_Firearm_Test_lowres.pd f (accessed 29 October 2018)

7. Ç. Akman, T. Sönmez, Ö. Özuğur, A.B. Başl1, M.K. Leblebicioğlu, Sensor Actuat. A-Phys., 271, 66-75 (2018)

8. N. Pathrose, K.R. Nair, R. Murali, K.R. Rajesh, N. Mathew, S. Vishnu, Analysis of acoustic signatures of small firearms for gun shot localization, Proceedings of 2016 IEEE Annual India Conference (INDICON), Bangalore, India (2016)

9. A. Ramos, On Acoustic Gunshot Localization Systems, Proceedings of the 20th International Conference of Society for Design and Process Science SDPS-2015, Fort Worth, TX, USA, 558$565(2015)$

10. M. Hrabina, M. Sigmund, Acoustical detection of gunshots, Proceedings of the 25th International Conference Radioelektronika, Pardubice, Czech Republik, 150-153 (2015)

11. K.Sh. Choi, M. Librett, T.J. Collins, Police Pract. Res., 15(1), 48-61 (2014)

12. R\&D Conference Staff, Sensor Can Instantly Detect Gunshots, ID Weapons During School Shootings, https://www.rd100conference.com/news/item/130/sensor-caninstantly-detectgunshots-id-weapons-during-school-shootings/

13. L. Chałko, P. Maciąg, M. Rucki, Application of acoustic emission signals pattern (to be published, Manufacturing 2019 conference at Poznan University of Technology, Poland (2019), accepted in February 2019)

14. L. Chałko, P. Maciąg, Scientific Letters of Rzeszow University of Technology, 35(298), 261-273 (2018)

15. C.M. Scala, R.A. Coyle, NDT International, 16(6), 339-343, (1983)

16. M.G.R. Sause, A. Gribov, A.R. Unwin, S. Horn, Pattern Recognit. Lett., 33(1), 17-23 (2012)

17. S. Li, Y. Song, G. Zhou, Measurement, 115, 39-44 (2018)

18. Zh. Li, H. Zhang, D. Tan, X. Chen, H. Lei, Process. Saf. Environ., 105, 32-40 (2017)

19. Sh. Zhu, Zh. Li, Sh. Zhang, L. Liang, H. Zhang, Measurement, 125, 48-55 (2018)

20. A. Hase, H. Mishina, Identification and evaluation of wear phenomena under electric current by using an acoustic emission technique, Tribol. Int., 127, 372-378 (2018)

21. F. Saeidi, S.A. Shevchik, K. Wasmer, Tribol. Int., 94, 112-117 (2016)

22. M. Qin, K. Wang, K. Pan, T. Sun, Zh. Liu, Appl. Acoust., 140, 275-282 (2018)

23. J. Liu, Y. Hu, B. Wu, Y. Wang, J. Manuf. Process., 35, 570-579 (2018)

24. A. Albers, T. Stürmlinger, K. Wantzen, Procedia CIRP, 63, 348-353 (2017)

25. A. Arun, K. Rameshkumar, D. Unnikrishnan, A. Sumesh, Materials Today: Proceedings, 5(5), Part 2, 11888-11899 (2018)

26. T. Segreto, S. Karam, R. Teti, J. Ramsing, Procedia CIRP, 28, $22-27$ (2015)

27. F. Dahmene, S. Yaacoubi, M. El-Mountassir, Physics Procedia, 70, 599-603 (2015)

28. A. Behnia, H.K. Chai, M. GhasemiGol, A. Sepehrinezhad, A.A. Mousa, Engineering Fracture Mechanics, In press, corrected proof, Available online 5 July 2018, https://doi.org/10.1016/j.engfracmech.2018.07.005 (2018) 
29. I. Bashir, J. Walsh, Ph.R. Thies, et al., Appl. Acoust. 121, 95-103 (2017)

30. T. Bohmann, M. Schlamp, I. Ehrlich, Composites Part B: Engineering, 155, 444-451 (2018)

31. B. Goszczyńska, G. Świt, W. Trąmpczyński, Archives of Civil and Mechanical Engineering, 16(4), 867-875 (2016)

32. Bruel\&Kjaer, Measuring Sound, Naerum, 1984 (Bruel\&Kjaer)

33. S. Dehaene, Trends Cogn. Sci., 7(4), 145-147 (2003)

34. Fabryka Broni „, Łucznik” - Radom sp. z o.o., Official Website, www.fabrykabroni.pl (accessed 29 October 2018) 